Avoiding the dark side of positive online consumer reviews: Enhancing its usefulness for high risk-averse travelers

\author{
Luis V. Casalóa (University of Zaragoza, Spain) \\ Carlos Flavián ${ }^{\mathrm{b}}$ (University of Zaragoza, Spain) \\ Miguel Guinalíu $u^{\mathrm{c}}$ (University of Zaragoza, Spain)

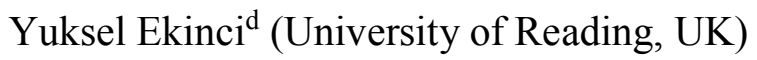

${ }^{a}$ Luis V. Casaló. Associate Professor of Marketing. Facultad de Empresa y Gestión Pública, University of Zaragoza, Plaza Constitución s/n, 22001, Huesca (Spain). E-mail: lcasalo@unizar.es.

${ }^{\mathrm{b}}$ Carlos Flavián. Professor of Marketing. Facultad de Economía y Empresa, University of Zaragoza, C/ Gran Vía 2, 50005, Zaragoza (Spain). E-mail: cflavian@unizar.es. Tel.: +34 976 762719. Corresponding author.

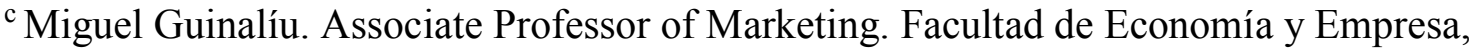
University of Zaragoza, C/ Gran Vía 2, 50005, Zaragoza (Spain). E-mail: guinaliu@,unizar.es. ${ }^{d}$ Yuksel Ekinci. Professor of Marketing. The School of Marketing and Reputation, Henley Business School, University of Reading, Reading (UK), RG6 6AU. E-mail: y.ekinci@,henley.ac.uk. 


\title{
Avoiding the dark side of positive online consumer reviews: Enhancing its usefulness for high risk-averse travelers
}

\begin{abstract}
The influence of positive online consumer reviews on the traveler's decision making remains unclear. In this study, two experiments using positive and negative online consumer reviews are conducted to better understand perceived usefulness of the online reviews. Firstly, the study suggests that high risk-averse travelers find the negative online reviews more useful than positive reviews. Secondly, the high-risk averse traveler's perceived usefulness of the positive online reviews can be enhanced if the posting is made by a review expert that includes a travel product picture and having a well-known brand name. These findings offer interesting implications for both marketing theory and practice.
\end{abstract}

Keywords: online consumer reviews, expertise, risk aversion, usefulness. 


\section{Avoiding the dark side of positive online consumer reviews: Enhancing its usefulness for high risk-averse travelers}

\section{Introduction}

Online consumer reviews are an increasing phenomenon that influences consumers' choice and purchasing behavior. A recent study finds that 78 percent of British consumers state that online reviews influence their purchase decisions (RightNow, 2010). While consumers question the value of recommendations made by firms (e.g., Coker and Nagpal, 2013), the increasing popularity of online consumer reviews may be because consumers find fellow consumers' comments (e.g., Word of Mouth) more credible than information from other sources (Bansal and Voyer, 2000; Senecal and Nantel, 2004).

Online reviews likely exert greater influence the travelers' purchasing decisions due to travel's intangibility and higher perceived financial risks (e.g., Lin, Jones and Westwood, 2009). Online travel communities such as Tripadvisor or TravBuddy influence millions of travel decisions based on previous travelers' comments. Eighty-four per cent of Tripadvisor visitors state that fellow travelers' reviews influence their hotel booking decisions (Travelindustrywire.com, 2007). Dickinger (2011) concludes that online travel reviews (i.e., personal information channels) are more informative than formal communication channels (e.g., city tourist boards). In other words, travelers consider the content of online reviews more useful than other online information sources.

Depending on their valence, online consumer reviews can be classified into positive and negative forms. Positive reviews elicit more positive responses (i.e., attitude or intention to use) than negative ones (Vermeulen and Seegers, 2009). The extant literature suggests that negative consumer reviews influence consumer's decision making more than positive reviews (see Chevalier and Mayzlin, 2006; Papathanassis and Knolle, 2011). According to the social 
cognition theory, negative information is perceived to be more trustworthy (Pan and Chiou, 2011) and influential than positive information in forming impressions (e.g., Fiske, 1993; Sparks and Browning, 2011). However, some studies challenge this notion and argue that positive reviews affect consumers' decision making (e.g., Vermeulen and Seegers, 2009), while others show that the effect of positive reviews on consumer behavior is minimum or none (e.g., Duan, Gu and Whinston, 2008), suggesting mixed results of the influence of positive reviews on consumer decisions. Although previous literature investigates the persuasive nature of consumer reviews, only a few studies focuses on how travelers evaluate online consumer reviews (e.g., Sen and Lerman, 2007; Park and Lee, 2009; Mudambi and Schuff, 2010), especially in the travel industry. Further investigation is necessary to better understand the impact of online reviews, because perceived usefulness is an important belief that influences travelers' decision making (e.g., Davis, Bagozzi and Warshaw, 1989; Karahanna, Straub and Chervany, 1999; Park and Lee, 2009).

This study investigates perceived usefulness of online hotel reviews. Online reviews constitute an important aspect of marketing communication because messages are shared between consumers. Accordingly, the study's objectives are two-fold. First, do travelers weigh positive and negative online reviews the same? Specifically, this study examines whether or not risk-aversion influences on the travelers' perceptions of positive and negative online reviews. Regulatory-focus theory suggests negative reviews are more persuasive when consumers aim to avoid negative end-states (Higgins, 1997; Zhang, Craciun, and Shin, 2010). Second, do certain features of online customer reviews enhance their perceived usefulness? Accordingly, this study considers three characteristics of online reviews: (1) the expertise of the information source (expert vs. non-expert reviewers), (2) the graphical content (product picture vs. none), and (3) the product familiarity (known vs. unknown products). Do consumers use these informational cues to reduce uncertainty? Prior research 
suggests these signals influence consumer evaluations of information to a great extent (e.g., Schlosser, White and Lloyd, 2006).

Based on the social cognition (e.g., Fiske, 1993; Sparks and Browning, 2011), communication (e.g., Chandler, 1994) and signaling theory (e.g., Schlosser et al., 2006), two experiments are conducted to investigate the role of risk aversion in explaining differences between perceived usefulness of positive and negative online reviews, and how to enhance positive online reviews for high risk-averse travelers. These findings help in the understanding of online consumer reviews and provide implications for both marketing theory and practice.

\section{Experiment I}

This experiment investigates differences between perceived usefulness of positive and negative online reviews. Previous social cognition studies (e.g., Fiske, 1993) find a strong relationship between risk aversion and the inherent characteristics of online travel products. Risk aversion reflects the individual's general tendency to avoid uncertainty (Hofstede, 1980; Matzler, Grabner-Krauter and Bidmon, 2008). High risk-averse people endeavor to reduce uncertainty by choosing more certain alternatives. Risk aversion is investigated widely by several disciplines such as psychology, economics, marketing or finance to explain managerial and consumer decision making (e.g., Jaworski and Kohli, 1993). For instance, risk aversion affects the company's market orientation (e.g., Jaworski and Kohli, 1993; Farrell, 2000), and consumer investments (e.g., Farsi, 2010), consumption decisions (e.g., Bao, Zhou and Su, 2003; Tan, 1999) and brand loyalty (e.g., Matzler et al., 2008). Consumer risk aversion varies depending on the product type (goods or services) and consumption contexts (e.g., internet vs. traditional retail formats) (Weber, Blais and Betz, 2002; Matzler et 
al., 2008). Therefore, travelers' risk aversion is a crucial factor when evaluating online consumer reviews due to the greater uncertainty of both online purchasing and purchasing travel services.

\subsection{Hypotheses}

Previous studies on online consumer reviews (e.g., Chevalier and Mayzlin, 2006; Sparks and Browning, 2011; Papathanassis and Knolle, 2011) and the social cognition theory (Fiske, 1993) suggest that negative reviews have greater influences on consumer behavior than the positive ones. Although some studies conclude positive reviews affect consumers' decision making (e.g., Vermeulen and Seegers, 2009), other studies suggest that the impact of positive reviews is very minimal (e.g., Duan et al., 2008). Since perceived usefulness likely affects consumer purchasing decisions (Davis et al., 1989; Karahanna et al., 1999), travelers should find negative online reviews more useful than those that are positive.

H1: The negative online consumer review is perceived to be more useful than one that is positive.

Interpersonal attributes of travelers may affect perceived usefulness of online consumer reviews (Zhu and Zhang, 2010). Because travel products and online shopping are highly intangible, internet purchases constitute higher uncertainty and risks. Risk aversion is thus a personal characteristic relevant to this study. Previous research shows that people who perceive higher risk seek Word-of-Mouth (WOM) communication more actively than those who perceive lower risk (Arndt, 1967). WOM serves as a credible source of information to assess risk and reduce uncertainty of purchase decisions (Murray, 1991). Online reviews likely are more useful for the risk-averse travelers who try to avoid risks. 
H2: High-risk-averse travelers find online reviews more useful than those that are low-risk-averse.

Finally, social cognition theory suggests that "people tend to place greater emphasis on negative information as it is more alerting" (Sparks and Browning, 2011, p. 1318; Fiske, 1993). An interaction effect between valence of online reviews and level of risk aversion is likely to exist. High risk-averse travelers are more likely to search information from online consumer reviews to avoid uncertainty. To avoid the risk of making wrong decisions, a high risk-averse traveler may find negative reviews more useful than positive ones. As suggested by the loss aversion theory, high risk-averse people are more sensitive to losses than to gains (Kahneman and Tversky, 1979).

H3: High risk-averse travelers will perceive a greater difference between usefulness of negative and positive online reviews than low risk-averse travelers.

\subsection{Methodology}

To test the research hypotheses, data were collected from a sample of Spanish travelers in October 2012. Customers from one of the largest Spanish online travel agencies (http://www.centraldereservas.com/) participated in the first experiment $(n=92)$. The sample was balanced in terms of gender (51.1\% female, $48.9 \%$ male) and age groups (less than 35 years $29.3 \%, 35-44$ years $43.5 \%$, 45 years or more $27.2 \%$ ). Most participants held a university degree $(54.3 \%)$ and the sample's demographic profile is similar to internet users in Spain (AIMC, 2012).

The experiment was promoted on the travel agency's website and an online link to the experiment was sent to the registered users. Participants were told they should imagine 
themselves looking information regarding the hotel under review and were instructed to read the online review presented to them. After accessing the experiment, forty-six participants were assigned randomly to the positive online review condition and forty-six participants to the negative online review. In addition to perceived usefulness of the online reviews, participants were also asked to provide socio-demographic information (age, gender, and education level). The online survey collected respondents' IP addresses to minimize the likelihood of multiple responses from one person.

The positive and negative online reviews were developed based on the most cited customer comments about hotels (price-quality relationship, location, comfort, staff attitude towards guests, and cleaning). To increase the experiment's external validity, online reviews were developed using examples posted on TripAdvisor.com which is the largest online travel network in Europe (O’Connor, 2008). Customer reviews reflecting the two experimental conditions were pre-tested with a sample of thirty volunteers. Using a five-point scale $(1=$ the most negative and $5=$ the most positive) and an independent samples t-test, the results revealed that the manipulation was successful $\left(\mathrm{t}_{(90)}=21.168, \mathrm{p}<0.01\right)$. Accordingly, positive consumer reviews were found to be more positive $(\mathrm{M}=4.48 ; \mathrm{SD}=0.72)$ than negative reviews $(\mathrm{M}=1.50 ; \mathrm{SD}=0.62)$.

Perceived usefulness of the online review was measured by a seven-point Likert scale (1 = "strongly disagree"; 7 = "strongly agree"; see Appendix 1). This scale is based on three items adopted from previous studies (Casaló, Flavián and Guinalíu, 2010; Wu and Chen, 2005; Bhattacherjee, 2001). Cronbach's alpha suggest the scale's reliability is acceptable ( $\alpha=0.81$ ), exceeding Nunnally's (1978) recommendation. Finally, risk aversion was measured by the statement: "I normally make decisions only if I am very certain of the final result" (Jaworski and Kohli, 1993). Travelers were divided in high and low risk-averse groups according to the arithmetic mean of this measure $(\mathrm{M}=5.40 ; \mathrm{SD}=1.13)$. 


\subsection{Findings}

To test $\mathrm{H} 1$ and $\mathrm{H} 2$, the dependent variable is perceived usefulness and the independent variables are valence of the online consumer review (positive vs. negative) and travelers' risk aversion (low vs. high). Independent sample t-tests in Table 1 show that both types of online reviews are found to be useful by travelers. As suggested by H1, perceived usefulness of negative online reviews were perceived more useful $(M=5.63)$ than positive reviews $(\mathrm{M}=5.28)$. As $\mathrm{H} 1$ is a directional hypothesis, the difference is statistically significant at the 90 percent level of confidence $(t=-1.67, p<0.10)$. To analyze this relationship in more detail, correlation between perceived usefulness of the review and the perceived positivity-negativity of the review was confirmed $(r=-0.18, p=0.09)$. Again, perceived usefulness seems to be slightly higher when online reviews are negative; supporting H1 $(\mathrm{p}<0.10)$. Table 1 shows low risk-averse travelers perceive usefulness of online reviews slightly higher $(M=5.56)$ than high risk-averse travelers $(M=5.36)$; however the mean difference was not statistically significant $(t=0.95, p>0.10)$ and does not support $\mathrm{H} 2$.

\section{TABLE 1 HERE}

A two-way ANOVA tested the interaction effect proposed in $\mathrm{H} 3$ (see Figure 1). Accordingly, the low risk-averse travelers' perceptions of the usefulness of the negative $(\mathrm{M}=$ 5.52) and positive $(\mathrm{M}=5.61)$ online reviews are similar $(\mathrm{p}<0.05)$.

\section{FIGURE 1 HERE}


In turn, the high risk-averse travelers find the negative online reviews more useful (M $=5.74)$. Positive online reviews' perceived usefulness decreases $(M=4.99)$, demonstrating in a greater difference between them. These results demonstrate a significant interaction effect for perceived usefulness of the online review $(\mathrm{F}=4.24, \mathrm{p}<0.05)$ and support H3.

To further investigate the interaction effect, the omega squared $\left(\omega^{2}\right)$ tested the strength of association between the valence and perceived usefulness of the online review for both low and high-risk-averse travelers. Omega squared results are interpreted as low $\left(\omega^{2} \leq 0.01\right)$, medium $\left(0.01<\omega^{2}<0.14\right)$, and high $\left(\omega^{2} \geq 0.14\right)$ association (Kirk, 2007). For the low riskaverse travelers, the omega squared test shows no effect of the online reviews' valence $\left(\omega^{2}<\right.$ 0.01, no effect). However, omega squared results show a statistically significant, medium association level for the high risk-averse travelers $\left(\omega^{2}=0.09\right)$, supporting the interaction effect.

\subsection{Discussion}

Experiment I results suggest that risk adverse travelers find negative online reviews more useful than those that are positive. As predicted positive online reviews seems to be less useful for the high risk-averse travelers. This result contributes to the extant literature on social cognition (e.g., Fiske, 1993) and online reviews (e.g., Chevalier and Mayzlin, 2006; Sparks and Browning, 2011; Papathanassis and Knolle, 2011) and helps to explain the perceived usefulness of online reviews from the point of view of the risk-averse travelers. Accordingly, perceived usefulness of negative information seems to be greater than that of positive information for high risk-averse travelers. This result is consistent with Zhang et al's (2010) conclusion in that negative consumer reviews are more persuasive when consumers try to avoid negative end states in their consumption. 
These results suggest a need for further investigation to determine how positive online reviews can better serve high risk-averse travelers. Experiment II investigates this proposition in greater detail.

\section{Experiment II}

The second experiment examines whether or not three basic communication cues enhance perceived usefulness of positive reviews for the high risk-averse traveler. These clues are: (1) the expertise of the information source (expert vs. non-expert reviewers); (2) the inclusion of graphical content in the text (product picture vs. no product picture); and (3) the product familiarity (known vs. unknown products). These communication cues potentially reduce perceived uncertainty and risk of purchasing. Prior online shopping research finds such signaling to be very effective (e.g., Schlosser et al., 2006). Arguably, high risk-averse travelers use these three communication cues to assess the perceived usefulness of positive online reviews.

\subsection{Hypotheses}

\subsubsection{Main effects}

Several studies investigate the expertise and influence of WOM on consumers' purchasing decision (e.g., Vermeulen and Seegers, 2009; Bansal and Voyer, 2000). Expert reviewers tend to be more persuasive because they have greater knowledge about the reviewed topic and awareness about different alternatives available in the market (Bansal and Voyer, 2000). Dickinger (2011) questions travelers' capability to produce high-quality information within online reviews. However, the expert information provider can employ his/her communication skills and knowledge on the topic to increase the review's usefulness. 
A positive online review made by an expert is likely to be more useful than an online review made by the non-expert.

H4: A positive online review made by an expert is perceived to be more useful than a positive online review made by the non-expert.

Product familiarity and product reputation is also likely to affect the usefulness of the review. Positive reviews of well-known products are likely have lower value to travelers because they already formed stable beliefs about the travel product. For unknown service providers, travelers likely have doubts about the travel product's benefits. In this scenario, travelers likely seek more information to reduce the uncertainty of their purchasing (e.g., Murray, 1991; Still, Barnes and Kooyman, 1984).

H5: A positive online review of an unknown travel product is perceived to be more useful than a positive online review of a well-known travel product.

Usually, online consumer reviews are text-based messages. Graphical contents added to online reviews may reduce uncertainty, particularly when purchasing intangible travel products (i.e., hotel services) (Zeithaml and Bitner, 1996; Lin et al., 2009). Pictures capture the details of how guests view a hotel better than traditional feedback methods, and both texts and pictures provide a richer source of information (Pullman and Robson, 2006). The product picture gives a tangible reference point about the travel product and helps travelers to better assess its benefits and credibility. The inclusion of a travel product picture (e.g., hotel) likely increases the review's perceived usefulness. Thus, we propose that: 
H6: A positive online review with a picture of the travel product is perceived to be more useful than a text only positive online review.

\subsubsection{Interaction effects}

A non-expert online review's credibility may be enhanced if the travel product is well-known. A familiar brand name enhances information processing and adds tangibility to the travel services (Diefenbach, 1992). The brand name also helps to improve perceived credibility and usefulness of the online review made by non-expert consumers. If an unknown travel product receives a positive online review by a nonexpert, it can make the assessment of credibility of the review difficult. The high risk-averse traveler will find this type of review less useful. On the other hand, an expert's positive online review of an unknown travel product will likely be more credible and useful. Signaling theory (e.g., Schlosser et al., 2006) suggests that the reviewer's expertise is a cue that enhances credibility of the message.

H7: The reviewer's expertise affects the perceived usefulness of a positive online review in a greater extent when the travel product is unknown.

The inclusion of a travel product picture may enhance the high risk-averse traveler's perceived usefulness of the positive online review made by a non-expert. Added graphical content likely increases the review's credibility, particularly in relation to risky purchasing decisions. 
H8: The inclusion of a travel product picture affects the perceived usefulness of a positive online review to a greater extent when the online review is made by a nonexpert.

When the travel service provider is unknown, a way of making the travel service more tangible and more credible can be achieved by adding a product picture in the review. Wellknown brands reduce the uncertainty of purchasing, serving as a more tangible reference point in assessing product benefits (Diefenbach, 1992). Following this line of thinking, including a product picture in a positive online review of an unknown travel product likely enhances the posting's perceived usefulness.

H9: The inclusion of a picture of the travel product affects the perceived usefulness of a positive online review to a greater extent when the travel product brand name is unknown.

\subsection{Methodology}

To test $\mathrm{H} 4$ to $\mathrm{H} 9$, an experiment design was formed. This consisted of $2 \times 2 \times 2$ (reviewer expertise $\mathrm{x}$ knowledge of the travel product $\mathrm{x}$ product picture). As before, travelers who registered onto one of the largest Spanish online travel agency websites participated in this experiment (http://www.centraldereservas.com/). Data were collected only from those participants who reported to be risk-averse travelers in Experiment I $(n=165)$. Crosschecking the final sample with the travel agency's customers found the sample to be representative by gender ( $50.9 \%$ female, $49.1 \%$ male) and age groups (less than 35 years $30.9 \%, 35-44$ years $39.4 \%, 45$ years or more $29.7 \%$ ). Participant's socio-demographics are similar to the average internet user in Spain (AIMC, 2012). 
Similar to Experiment I, the registered travel agency customers were sent an online link relating to hotel travel reviews. After accessing the experiment, participants were randomly assigned to a positive online review that had been manipulated according to three different criteria; an expert or non-expert, a known or unknown hotel, with or without a hotel picture. Participants were asked to imagine themselves looking for information regarding the hotel under review. After reading the online hotel review, participants were asked to respond to questions about their socio-demographic characteristics (age, gender and education level), along with the perceived usefulness of the online review. Finally, it was ensured that no participant within Experiment I could participate in Experiment II, neither could participants in Experiment II access the experiment more than once. To ensure this accuracy the contact details of participants were checked along with their IP addresses from which they accessed the experiment. At the end of this process, each scenario had a minimum of nineteen assigned participants and a maximum of twenty-seven completing all questions.

Review expertise was manipulated by referring to the reviewer as either "a 3-star top reviewer responsible for conducting twenty-seven previous reviews" or "a novel reviewer performing his/her first review". These characteristics are often presented in order to qualify their expertise in the context of online abilities. Using a five-point numeric scale $(1=$ the least expert, $5=$ the most expert) along with an independent samples t-test, the findings show that manipulation was successful $\left(\mathrm{t}_{(163)}=19.49, \mathrm{p}<0.01\right)$. Participants agreed that the expert reviewer had more expertise $(M=4.18 ; \mathrm{SD}=0.85)$ than the non-expert reviewer $(\mathrm{M}=1.72$; $\mathrm{SD}=0.77)$. Product knowledge regarding the hotel was manipulated through the inclusion of a well-known hotel brand and an unknown one. Pre-test results, based on a sample of thirtyfive participant opinions, showed that $\mathrm{NH}$ was the most known brand. Accordingly the "NH Hotel" brand was selected for the known condition, with the name "Hotel Alanda" for the unknown condition. All participants of this experiment stated that they knew something about 
NH Hotels, whilst none reported any knowledge regarding Hotel Alanda. This confirmed the successful manipulation of the experiment. Finally, a picture of the hotel was included within the online reviews. Whilst the hotel picture was the same for both known and unknown conditions, the scenarios were distinguished by eliminating the $\mathrm{NH}$ brand name in the unknown hotel category, as seen in Figure 2. Participants responding to the online review with a hotel picture scenario confirmed that they saw the picture before responding to the Experiment II questions.

\section{INSERT FIGURE 2}

In turn, the perceived usefulness of online review was measured using the same scales as in Experiment I. Again, Cronbach's alpha statistic is applied to assess the reliability of this measure. The result is a score of 0.90 , which is over the minimum acceptable reliability score of 0.70 (Nunnally, 1978).

\subsection{Findings}

To test the main effects proposed in hypotheses H4 to H6, three independent samples t-tests on the perceived usefulness measure were conducted. Results in Table 2 show that positive online reviews are more useful when performed by expert reviewers than nonexperts $(\mathrm{M}=5.60$ and $\mathrm{M}=5.25$ respectively). The mean difference was statistically significant at the 0.90 percent level of confidence as the proposed directional hypothesis $(\mathrm{t}=$ $1.75, \mathrm{p}=0.08)$. 
To check this relationship in greater detail, correlation analysis was conducted between the perceived expertise of the reviewer and the perceived usefulness of the review. The results reveal a significant positive correlation $(r=0.17, p<0.05)$. Therefore, $\mathrm{H} 4$ is supported. Although positive online reviews having a hotel picture are a little more useful than those without $(\mathrm{M}=5.56$ and $\mathrm{M}=5.27$ respectively $)$, the mean difference is not statistically significant $(\mathrm{t}=1.42, \mathrm{p}>0.10)$. So H6 is rejected. Finally, contrary to expectations, perceived usefulness of positive reviews for well-known hotels was greater than for unknown hotels $(M=5.70$ and $M=5.11$ respectively; $t=2.97 ; p<0.01)$. Therefore, hypothesis 5 is rejected too. This might be due to the fact that a well-known brand helps to increase the credibility of online reviews. It is more difficult to assess the credibility of positive online reviews in relation to unknown hotels (e.g. the high risk-averse traveler may have no belief in the travel product). Therefore, the perceived usefulness of positive online reviews might increase in relation to well-known travel products.

A two-way ANOVA tested the interaction effects. Firstly, it is interesting to acknowledge that positive online reviews made by expert reviewers are almost equally useful for both known and unknown hotels $(\mathrm{M}=5.75$ and $\mathrm{M}=5.45$ respectively). This interaction effect can be seen in Figure 3.A.

\section{FIGURE 3 HERE}

However, perceived usefulness of the review made by non-experts is much greater for the known hotel than the unknown $(\mathrm{M}=5.71$ and $\mathrm{M}=4.77$ respectively). Hence $\mathrm{H} 7$ is supported at the 0.90 percent level of confidence $(F=2.81, p=0.09)$. Indeed, the strength of association between hotel brand name and perceived usefulness of the review is much greater 
when the reviewer is a non-expert $\left(\omega^{2}=0.01\right.$, medium effect $)$ than when the reviewer is an expert $\left(\omega^{2}<0.01\right.$, no effect $)$, which reinforces the interaction effect proposed in $\mathrm{H} 7$.

A second interaction effect in relation to the inclusion of hotel pictures within online reviews is also supported $(\mathrm{F}=3.62, \mathrm{p}<0.05)$. As can be seen in Figure 3.B, the usefulness of online reviews in relation to an unknown hotel is much greater when a picture is included than without $(\mathrm{M}=5.44$ and $\mathrm{M}=4.79$ respectively). However, when the hotel is known, perceived usefulness of the online review is almost the same for both conditions whether the hotel picture is included or not $(\mathrm{M}=5.69$ and $\mathrm{M}=5.77$ respectively). This finding supports H9 at the 0.90 percent level of confidence. Again, the $\omega^{2}$ serves to reinforce the interaction effect showing the strength of association between the inclusion of a picture and perceived usefulness of the review which is much greater when the hotel is unknown $\left(\omega^{2}=0.06\right.$, medium effect) than when the hotel is known $\left(\omega^{2}<0.01\right.$, no effect).

Finally, there is no support for H8, as the interaction effect between reviewer expertise and the inclusion of a hotel picture under review is not statistically significant as shown in Figure 3.C $(\mathrm{F}=2.27, \mathrm{p}>0.10)$. Indeed, contrary to expectations, when there is no picture in the online review, perceived usefulness of reviews made by experts is similar to the reviews made by non-experts $(\mathrm{M}=5.31$ and $\mathrm{M}=5.25$ respectively). In turn, when the picture is included, perceived usefulness of the online reviews made by experts increases immensely $(M=5.89)$, while perceived usefulness of the reviews by non-experts remain almost the same $(\mathrm{M}=5.24)$. According to the strength of association, it seems that the inclusion of a picture is more relevant in the case of expert reviewers $\left(\omega^{2}=0.06\right.$, medium effect $)$ than that of nonexpert reviewers $\left(\omega^{2}<0.01\right.$, no effect).

\subsection{Discussion}


The findings of Experiment II suggest that the perceived usefulness of positive online reviews by high risk-averse travelers can be enhanced by different marketing communication tactics. When the travel service provider is well-known, product pictures and reviewer expertise are not critical to enhance the perceived usefulness of positive online reviews. The predetermined beliefs in well-known brands serve to assess the perceived risk. Fewer social and marketing cues are needed to increase the usefulness of positive online reviews. However, when the travel service provider is unknown, the reviewer expertise and product picture appear to enhance the perceived usefulness of the review.

These results have important implications for managers of both known and unknown travel providers: The former should focus their efforts on increasing their number of positive online reviews. The latter should focus on increasing the number of positive reviews made by experts. In this case, the online consumer reviews should also include a picture of the travel product in order to reinforce positive information. It is therefore possible to enhance the perception of high risk-averse travelers in the usefulness of positive online reviews.

\section{Conclusions}

This paper is an attempt to better understand the perceived usefulness of online consumer reviews. The two experimental results suggest that: (1) negative online reviews are perceived to be more useful than those that are positive, (2) this difference is particularly relevant to high risk-averse travelers, who find negative reviews much more useful than those that are positive; and (3) a combination of different signaling tactics may enhance the perceived usefulness by high risk-averse travelers through positive online reviews. These cues are review experts, inclusion of product pictures and brand names. These findings have interesting implications for both marketing theory and practice. Theoretically, this work advances previous literature based upon online consumer reviews (e.g. Vermeulen and 
Seegers, 2009; Sparks and Browning, 2011) by (1) clarification as to whether the perceived usefulness of online reviews differs between high and low risk-averse travelers. This will add to previous findings based on the social cognition theory that people are more affected by negative information (e.g., Sparks and Browning, 2011), particularly high risk-averse travelers who consider positive reviews less useful, and (2) explaining under which conditions perceived usefulness of positive online reviews could be enhanced for high riskaverse travelers. This could be achieved through the inclusion of information cues such as reviewer expertise, brand names and graphical content.

On the practical side, travel marketers should firstly encourage their consumers to post online reviews. Potential travelers generally find these reviews useful in assessing travel product benefits and the perceived uncertainty of online purchasing. Secondly, to enhance the perceived usefulness of positive online reviews to high risk-averse travelers, review experts should perform the task and include graphical content where the travel product is unknown. Accordingly, it is particularly relevant to travel marketers to identify those people with greater expertise. This will motivate them to post positive reviews regarding their consumption experiences. To encourage this, managers can access new technologies having increasing popularity such as Klout (http://klout.com). This platform evaluates the influence of social media users and provides the knowledge as to which topics have the greatest influence. Similarly, new online tools that specialize in specific networks have been developed such as SocialBro (http://www.socialbro.com/), which allows the identification of the most influential users of Twitter. Additionally, it is relevant to motivate consumers to include pictures with their reviews (or on any other online generated content) when the travel product is not well-known. In relation to this, Foursquare (https://foursquare.com/), a location-based network, may be very useful for this purpose as it allows users to post their location, add pictures and make comments using only a mobile device such as a tablet or 
smart-phone. In the case of well-known travel products, reviewer expertise with the inclusion of a picture becomes less relevant in increasing the perceived usefulness of online consumer reviews by high risk-averse travelers. This finding suggests that travel marketers should also develop policies to improve brand image and reputation. In sum, these tactics would help to increase the usefulness of positive online consumer reviews to high risk-averse travelers, and thus obtain more benefits derived from their decisions based on those reviews.

Finally, this work has limitations and new avenues for further research. It is important to note that the sample is formed by consumers of a Spanish online travel agency (http://www.centraldereservas.com/). Although the sample is well-balanced in terms of demographics and representative of the travel agency consumers, it would be useful to confirm external validity of these results through participants from different nationalities and cultures. In addition, a specific travel product (hotel) was selected as the object under review. Due to the unique characteristics of the travel product, risk aversion was considered an important and relevant interpersonal attribute to assess the perceived usefulness of online consumer reviews. Results may differ if products or service from other industries are used and other interpersonal characteristics are included (e.g. susceptibility to interpersonal influence). Also, the study used an experience based travel product (i.e., hotel service). Hence it is usually difficult to observe hotel quality in advance. Previous studies suggest that extreme positive and negative online reviews are particularly helpful for search rather than experience based products (Mudambi and Schuff, 2010). Thus, it may be helpful to replicate the study by focusing on search goods (i.e., a digital camera) rather than services. Finally, inherent characteristics of the online consumer reviews were considered; however, other aspects such as length, style of review, the online review publication site, etc., may also affect the perceived usefulness of the review. These recommendations would help to enhance generalizability of this research finding. 


\section{References}

AIMC. Navegantes en la red, $14^{\circ}$ encuesta AIMC a usuarios de Internet. Madrid (Spain): Asociación para la Investigación de Medios de Comunicación; 2012.

Arndt J. Role of Product-Related Conversations in the Diffusion of a New Product. $J$ Marketing Res 1967; 4 (August): 291-95.

Bansal HS, Voyer PA. Word-of-Mouth Processes Within a Services Purchase Decision Context. J Service Res 2000; 3 (2): 166-77.

Bhattacherjee A. Understanding Information Systems Continuance: An Expectation/Confirmation Model. MIS Q 2001; 25 (3): 351-70.

Bao Y, Zhou KZ, Su C. Face Consciousness and Risk Aversion: Do They Affect Consumer Decision-Making? Psychol \& Marketing 2003; 20 (8): 733-55.

Bucklin RE, Sismeiro C. A model of web site browsing behavior estimated on clickstream data. J Marketing Res 2003; 40 (3): 249-67.

Casaló LV, Flavián C, Guinalíu M. Determinants of the intention to participate in firm-hosted online travel communities and effects on consumer behavioral intentions". Tourism Management 2010; 31 (6): 898-911.

Chandler D. The Transmission Model of Communication. University of Western Australia. Available at: http://www.aber.ac.uk/media/Documents/short/trans.html; 1994. Accessed 15.10.2014.

Chevalier JA, Mayzlin D. The effect of word-of-mouth on sales: Online Book Reviews. $J$ Marketing Res 2006; 43 (3): 345-54.

Coker B, Nagpal A. Building-Up versus Paring-Down: Consumer Responses to Recommendations When Customizing. J Retail 2013; 89 (2): 190-206.

Davis FD, Bagozzi RP, Warshaw PR. User acceptance of computer technology: A comparison of two theoretical models. Management Sci 1989; 35 (8): 982-1003. 
Dickinger A. The Trustworthiness of Online Channels for Experience- and Goal-Directed Search Tasks. J Travel Res 2011; 50 (4): 378-91.

Diefenbach J. The Corporate Identity as the Brand. In JM Murphy (ed.), Branding: A Key Marketing Tool (pp. 155-64). Basingstoke: MacMillan; 1992.

Duan W, Gu B, Whinston AB. Do online reviews matter? - An empirical investigation of panel data. Decis Support Syst 2008; 45 (4): 1007-16.

Farrell MA. Developing a Market-Oriented Learning Organisation. Australian J Management 2000; 25 (2): 201-22.

Farsi M. Risk aversion and willingness to pay for energy efficient systems in rental apartments. Energy Policy 2010; 38 (6): 3078-88.

Fiske S. Social cognition and social perception. Annual Rev Psychol 1993; 44: 155-94.

Hofstede G. Culture's consequences: International differences in work-related values.

Newbury Park, CA: Sage; 1980.

Jaworski BJ, Kohli AK. Market-Orientation: The Construct, Research Propositions, and Managerial Implications. J Marketing 1993; 54 (April): 1-18.

Kahneman D, Tversky A. Prospect theory: and analysis of decision under risk. Econometrica 1979; 47 (2): 263-91.

Karahanna E, Straub DW, Chervany NL. Information technology adoption across time: A cross-sectional comparison of pre-adoption and post-adoption beliefs. MIS $Q$ 1999; 23 (2): $183-213$.

Kirk RE. Effect Magnitude: A Different Focus. J Statistical Plan Inference 2007; 137 (5): 1634-46.

Lin PJ, Jones E, Westwood S. Perceived Risk and Risk-Relievers in Online Travel Purchase Intentions. $J$ Hospitality Marketing \& Management 2009; 18 (8): 782-810. 
Matzler K, Grabner-Krauter S, Bidmon S. Risk aversion and brand loyalty: the mediating role of brand trust and brand affect. J Product \& Brand Management 2008; 17 (3): 154-62.

Mudambi S, Schuff D. What makes a helpful online review? A study of customer reviews on Amazon.com. MIS Q 2010; 34 (1): 185-200.

Murray KB. A Test of Service Marketing Theory: Consumer Information Acquisition Activities. J Marketing 1991; 55 (January): 10-15.

Nunnally JC. Psychometric Theory, (2 ${ }^{\text {nd }}$ ed.). New York: McGraw-Hill; 1978.

O'connor P. User-generated content and travel: a case study on tripadvisor.com. Inf Commun Technol in Tourism 2008; 2: 47-58.

Pan LY, Chiou JS. How Much Can You Trust Online Information? Cues for Perceived Trustworthiness of Consumer-generated Online Information. J Interact Marketing 2011; 25 (2): 67-74.

Papanasthassis A, Knolle F. Exploring the adoption and processing of online holiday reviews: a grounded theory approach. Tourism Management 2011; 32: 215-24.

Park C, Lee TM. Antecedents of Online Reviews' Usage and Purchase Influence: An Empirical Comparison of U.S. and Korean Consumers. J Interact Marketing 2009; 23 (4): $332-40$.

Pullman ME, Robson S. A Picture Is Worth a Thousand Words: Using Photo-elicitation to Solicit Hotel Guests' Feedback. Tools for the hospitality industry (CHR Tool No. 7). Cornell University, School of Hotel Administration, The Center for Hospitality Research; 2006.

RightNow. The socialization of customer experiences UK 2010. Available at: http://www.callcentre.co.uk/page.cfm/Action=Library $/$ libID $=1 /$ listID $=40 /$ libEntryID $=37$ 92; 2010. Accessed 22.01.2012. 
Schlosser AE, White TB, Lloyd SM. Converting Web Site Visitors into Buyers: How Web Site Investment Increases Consumer Trusting Beliefs and Online Purchase Intentions. $J$ Marketing 2006; 70 (April): 133-48.

Sen S, Lerman D. Why are you telling me this? An examination into negative consumer reviews on the Web. J Interact Marketing 2007; 21 (4): 76-94.

Senecal S, Nantel J. The influence of online product recommendations on consumers' online choices. J Retail 2004; 80 (2): 159-69.

Sparks BA, Browning V. The impact of online reviews on hotel booking intentions and perception of trust. Tourism Management 2011; 32 (6): 1310-23.

Still RR, Barnes Jr JH, Kooyman ME. Word-of-Mouth Communication in Low-Risk Product Decisions. International J Advertising 1984; 3: 335-45.

Tan SJ. Strategies for reducing consumers' risk aversion in Internet shopping. J Consum Marketing 1999; 16 (2): 163-80.

Travelindustrywire.com. Travel reviews - consumers are changing your brand and reputation online. Available at: http://www.travelindustrywire.com/article29359.html; 2007. Accessed 15.10.2014.

Vermeulen IE, Seegers D. Tried and tested: The impact of online hotel reviews on consumer consideration. Tourism Management 2009; 30: 123-27.

Weber EU, Blais AR, Betz NE. A domain-specific risk-attitude scale: measuring risk perceptions and risk behaviors. J Behav Decis Mak 2002; 15 (4): 263-90.

Wiertz C, de Ruyter K. Beyond the call of duty: Why customers contribute to firm-hosted commercial online communities. Organization Stud 2007; 28 (3): 347-78.

Wu IL, Chen JL. An extension of trust and TAM model with TPB in the initial adoption of on-line tax: An empirical study. International J Hum Computer Stud 2005; 62: 784-808.

Zeithaml VA, Bitner MJ. Services Marketing. New York: McGraw-Hill; 1996. 
Zhang JQ, Craciun G, Shin D. When does electronic word-of-mouth matter? A study of consumer product reviews. J Bus Res 2010; 63 (12): 1336-41.

Zhu F, Zhang X. Impact of Online Consumer Reviews on Sales: The Moderating Role of Product and Consumer Characteristics. J Marketing 2010; 174 (2): 133-48. 


\section{APPENDIX 1}

Below are the measures for the variables included in the research model. Respondents rate from 1 being "strongly disagree" to 7 being "strongly agree" the following statements in relation to the online hotel review presented to them. Specifically:

Perceived Usefulness (adapted from Casaló et al., 2010; Wu and Chen, 2005; Bhattacherjee, 2001)

USEF1. This online review provides relevant information about the hotel.

USEF2. This online review helps me form a more realistic image of the hotel.

USEF3. In general, this online review is useful.

Risk aversion (item borrowed from Jaworski and Kohli, 1993)

RISK AV. I normally make decisions only if I am very certain of the final result.

Note: These items were presented in Spanish due to the nationality of participants. 
Table 1. Means for perceived usefulness of the review

\begin{tabular}{|cccccc|}
\hline & $\begin{array}{c}\text { Positive Reviews } \\
(\mathrm{N}=46)\end{array}$ & $\begin{array}{c}\text { Negative Reviews } \\
(\mathrm{N}=46)\end{array}$ & t-value & $p$ & \\
$\begin{array}{c}\text { Perceived usefulness of the } \\
\text { online review }\end{array}$ & 5.28 & 5.63 & -1.67 & $0.09 *$ & H1 supported \\
\hline & $\begin{array}{c}\text { Low } \\
\text { Risk-Averse } \\
\text { Travelers (N=44) }\end{array}$ & $\begin{array}{c}\text { Risk-Averse } \\
\text { Travelers (N=48) }\end{array}$ & t-value & $p$ & \\
$\begin{array}{c}\text { Perceived usefulness of the } \\
\text { online review }\end{array}$ & 5.56 & 5.36 & 0.95 & 0.34 & H2 rejected \\
\hline
\end{tabular}

*Statistically significant at the 0.10 level 
Figure 1. Interaction effect: Means for perceived usefulness of the review

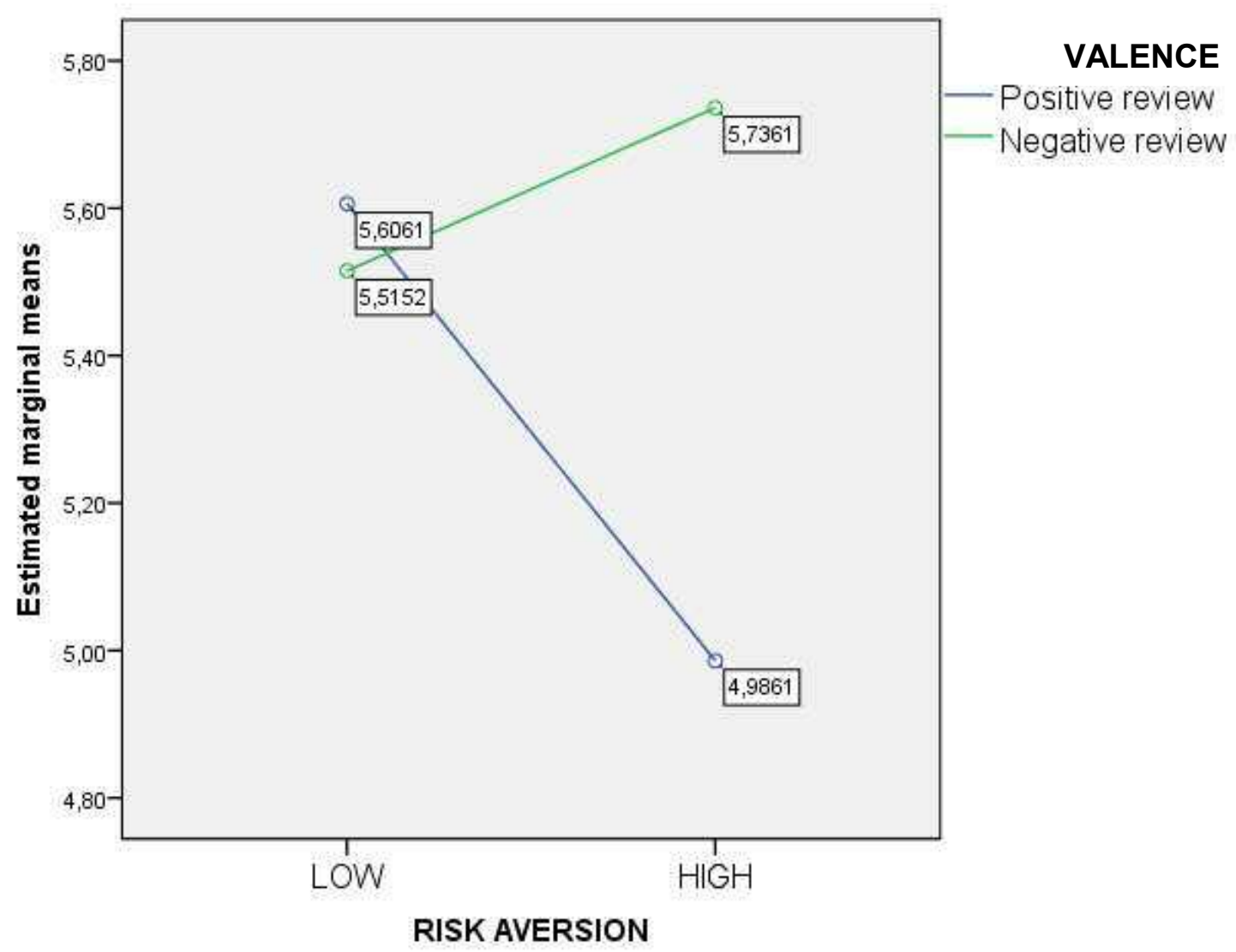


Figure2. Hotel images used in Experiment II

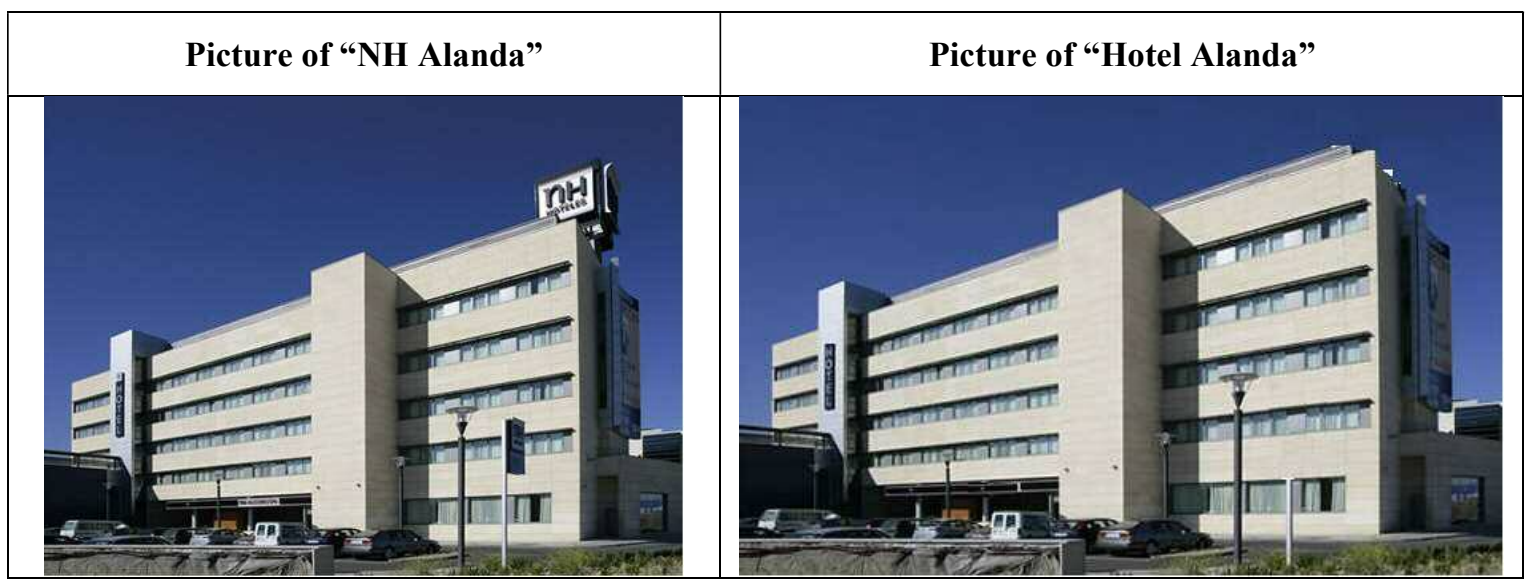


Table 2. Means for perceived usefulness of the positive online reviews

\begin{tabular}{|c|c|c|c|c|c|}
\hline \multirow[b]{2}{*}{$\begin{array}{l}\text { Perceived usefulness of } \\
\text { the online review }\end{array}$} & $\begin{array}{c}\text { Expert } \\
\text { Reviewer } \\
(\mathrm{N}=80)\end{array}$ & $\begin{array}{l}\text { Non-expert } \\
\text { Reviewer } \\
(\mathrm{N}=85)\end{array}$ & t-value & $p$ & \\
\hline & 5.60 & 5.25 & 1.75 & $0.08^{*}$ & H4 supported \\
\hline \multirow[b]{2}{*}{$\begin{array}{l}\text { Perceived usefulness of } \\
\text { the online review }\end{array}$} & $\begin{array}{l}\text { Known Hotel } \\
\quad(\mathrm{N}=86)\end{array}$ & $\begin{array}{l}\text { Unknown Hotel } \\
\qquad(\mathrm{N}=79)\end{array}$ & t-value & $P$ & \\
\hline & 5.70 & 5.11 & 2.97 & $0.00 * *$ & $\begin{array}{l}\text { H5 rejected } \\
\text { (effect contrary } \\
\text { to expected) }\end{array}$ \\
\hline \multirow[b]{2}{*}{$\begin{array}{l}\text { Perceived usefulness of } \\
\text { the online review }\end{array}$} & $\begin{array}{l}\text { With Picture } \\
\quad(\mathrm{N}=86)\end{array}$ & $\begin{array}{l}\text { Without Picture } \\
\qquad(\mathrm{N}=79)\end{array}$ & t-value & $P$ & \\
\hline & 5.56 & 5.27 & 1.42 & 0.15 & H6 rejected \\
\hline
\end{tabular}

*Statistically significant at the 0.10 level. ** Statistically significant at the 0.01 level 
Figure 3. Interaction effects: Means for perceived usefulness of positive online reviews

3.A

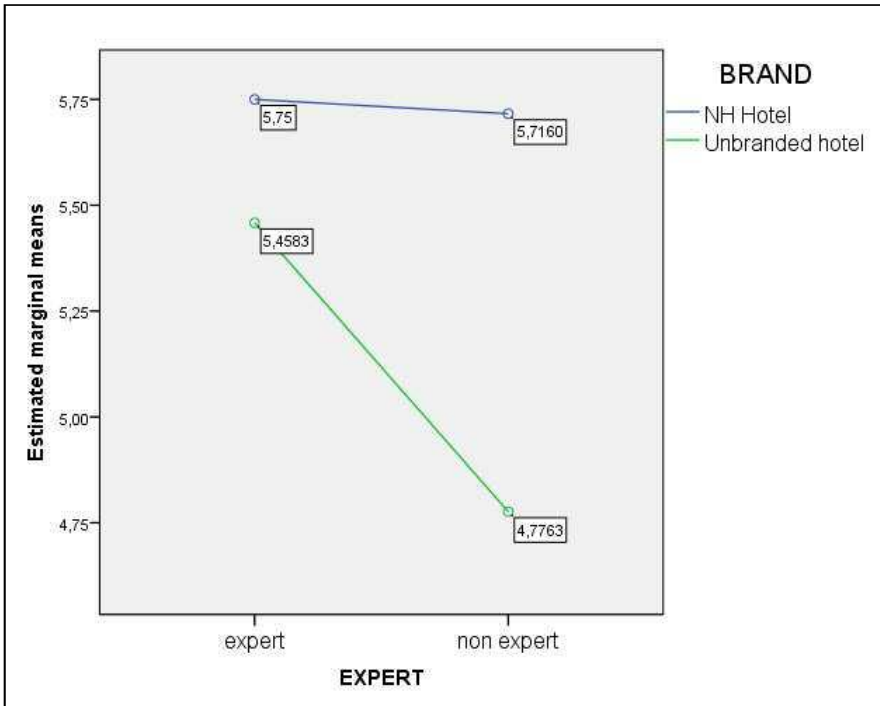

3.B

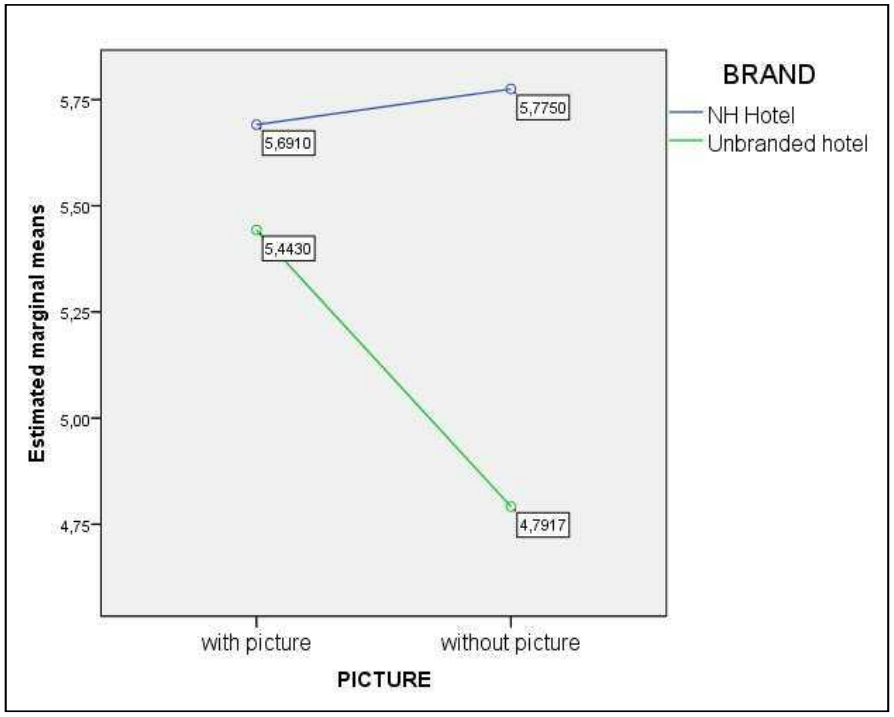

3.C

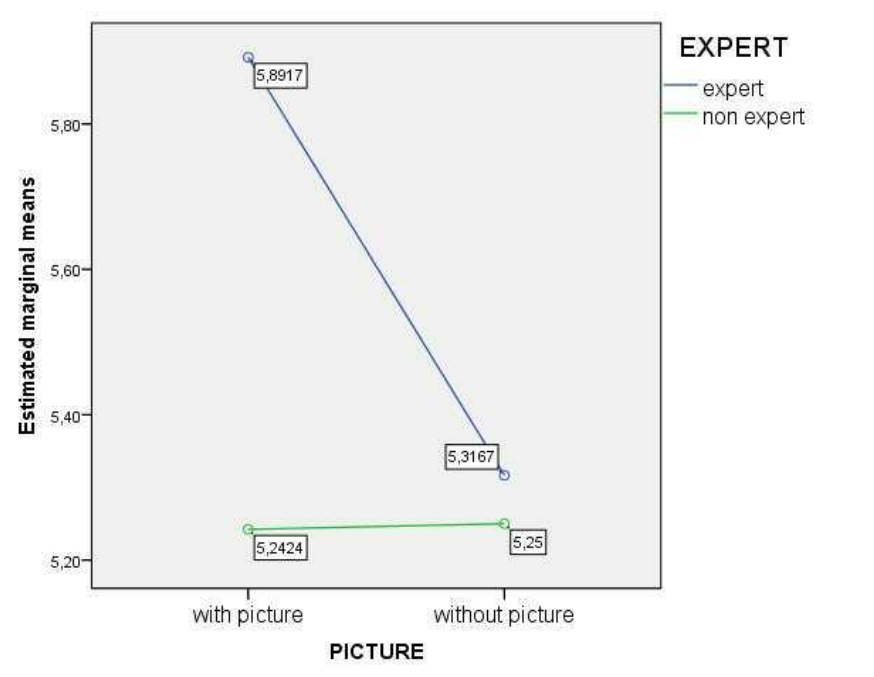

